\title{
Only serum pepsinogen I and pepsinogen I/II ratio are specific and sensitive biomarkers for screening of gastric cancer
}

https://doi.org/10.1515/bmc-2019-0010

received February 28, 2018; accepted March 12, 2019.

\begin{abstract}
Purpose: We aimed to determine optimal cut-off points of plasma levels of ghrelin and serum levels of pepsinogen I, II, and their ratio for screening of gastric cancer (GC).
\end{abstract}

Methods: Blood samples were taken from 41 patients with confirmed gastric cancer along with 82 patients without malignancy. Serum levels of pepsinogen I and II, plus plasma levels of acylated ghrelin were measured using commercial ELISA kits.

Results: The case group had significant lower plasma levels of ghrelin, pepsinogen I, and pepsinogen I/II ratio in comparison to the control group $(\mathrm{P}<0.001)$. In the control group, there was significant higher serum pepsinogen I $(\mathrm{P}=0.028)$ and pepsinogen II $(\mathrm{P}=0.003)$ and lower pepsinogen $\mathrm{I} / \mathrm{II}$ ratio $(\mathrm{P}=0.020)$ in males versus females; significantly higher serum pepsinogen II $(\mathrm{P}=0.047)$ and lower pepsinogen I/II ratio $(\mathrm{P}=0.030)$ in overweight compared to normal weight patients; and significantly lower pepsinogen $\mathrm{I} / \mathrm{II}$ ratio $(\mathrm{P}=0.030)$ in smokers versus non-smoker. In the case group, there was only significantly lower pepsinogen $\mathrm{I}(\mathrm{P}=0.006)$ in males versus females, and significantly lower plasma ghrelin $(\mathrm{P}=0.017)$ in overweight compared to normal weight patients. The characteristic curve analysis indicated that pepsinogen I at a cut-off of $70.95 \mu \mathrm{g} / \mathrm{L}$ and pepsinogen I/II ratio at cut-off of 2.99 , had good sensitivity and specificity.

\footnotetext{
*Corresponding author: Farahnaz Joukar, Gastrointestinal and Liver Diseases Research Center, Guilan University of Medical Sciences, Rasht, Iran, E-mail: Farajov@gmail.com

Fariborz Mansour-Ghanaei: Gastrointestinal \& Liver Diseases Research Center, Guilan University of Medical Sciences, Rasht, Iran Massood Baghaee: GI Cancer Screening and Prevention Research Center, Guilan University of Medical Sciences, Guilan University of Medical Sciences, Rasht, Iran

Masood Sepehrimanesh: GI Cancer Screening and Prevention Research Center, Guilan University of Medical Sciences, Rasht, Iran Amineh Hojati: Caspian Digestive Diseases Research Center,Guilan University of Medical Sciences, Rasht, Iran
}

Conclusions: Just serums levels of pepsinogen I and the ratio of pepsinogen $\mathrm{I} / \mathrm{II}$ can be used as biomarker to screen GC.

Keywords: Ghrelin; pepsinogen; gastric cancer (GC); biomarker.

\section{Introduction}

Despite an overall decline in gastric cancer (GC) incidences and mortality in the last century, it is still the fourth most common cancer and the second leading cause of cancer-related death worldwide [1-3]. There are definite differences in the incidence rates between and within countries [4]. In Iran, the northern and northwestern regions are high-risk areas for GC [5-7]. A fifteen year trend analysis in Guilan province showed a Stable situation of GC (trends of GC), plus an age standardized incidence rate of 14.5 per 100,000 for GC [8].

Upper gastrointestinal (UGI) endoscopy and histological examination of endoscopic biopsy are commonly used in the diagnosis of atrophic gastritis and premalignant lesions, as well as differentiation of diseased stomach mucosa from healthy mucosa. However, these techniques, mostly the biopsy sampling, are invasive and scientists are trying to find non-invasive methods. Evaluation of the amount of serum and plasma biomarkers such as pepsinogen (PG) I, II, PG I/II ratio, and ghrelin would be a non-invasive option $[9,10]$. Although, gastric PG I and II are produced by the chief cells in the gastric fundus, PG II is also produced by the pyloric glands in the antrum and Brunner's glands. A rise in the concentration of the both occurs because of inflammation. During atrophic gastritis, the serum levels of PG I decrease with the exception of PG II. The gastric mucosa morphological status is reflected in these alterations [11]. On the other hand, changes in ghrelin expression in patients with gastric atrophy has been investigated recently, suggesting 
its potential role as a marker of gastric mucosal function [12]. Additionally, a negative association between serum ghrelin and UGI cancers were reported [13, 14]. UGI endoscopy or Esophagogastroduodenoscopy (EGD) are the best standard methods for the diagnosis of UGI diseases, and remarkably powerful tools for therapeutic goals. For EGD, there are little studies measuring the quality of this method quality. Additionally, the lack of functions evaluates, which last much longer than for a colonoscopy, may be influencing EGD quality.

The aims of the present study were to evaluate and compare the serum levels of diagnostic biomarkers between control, healthy volunteers and patients with GC, and to find a cut-off value for each biomarker.

\section{Materials and Methods}

\section{Study design and setting}

This case-control study was performed to evaluate and compare the gastric markers between a healthy control group and patients with GCs from January 2014 to February 2015. Gastrointestinal and Liver Disease Research Center (GLDRC) of Guilan University of Medical Sciences funded this study. The Ethics Committee of Guilan University of Medical Sciences has approved the study design, protocols, and informed consent procedure. Forty-one patients with confirmed GCs in their body and antrum as confirmed by endoscopy, without any previous medical intervention, were considered as the case group. In addition, 82 patients, who underwent diagnostic endoscopy for any other reason without malignancy, served as the control group. Patients with previous gastric surgery or any other treatments for GC including chemotherapy or radiotherapy were excluded. After the recruitment, a checklist was completed for all patients, including age, sex, BMI, history of smoking, and alcohol consumption.

Ethical approval: The research related to human use has been complied with all the relevant national regulations, institutional policies and in accordance the tenets of the Helsinki Declaration, and has been approved by the Ethics Committee of Guilan University of Medical Sciences

Informed consent: Informed consent has been obtained from all individuals included in this study

\section{Tissue sampling}

For endoscopic evaluation, after two local anesthesia using 10\% Lidocaine (with 10 minute interval), an upper GI endoscopy (video-endoscope, GIF-Q240Z; Olympus Co., Tokyo, Japan) was performed by three experienced endoscopists and cooperation of a trained staff based on the standard guideline to decrease observer bias. The samples were fixed in $10 \%$ formalin, labeled with the subject's codes, and described by a blinded pathologist to decrease measurement bias. The diagnoses were consistent with protocol requirements regarding International Classification of Disease for Oncology $3^{\text {rd }}$ edition (ICD-O-3).

\section{Laboratory assessment}

To decrease measurement bias, all blood samples were analyzed in a single private laboratory. First, $5 \mathrm{~mL}$ blood samples were obtained after overnight fasting from cubical vein in resting condition. In this way, determination of serum levels of PG I and PG II were performed using a commercial ELISA assay (Gastropanel ${ }^{\circledR}$, BioKit ${ }^{\circledR}$, Helsinski, Finland), following the manufacturer's instructions. Measurement of acylated ghrelin in the plasma (ghrelin unit is $\mathrm{pg} / \mathrm{ml}$ ) was performed using a double-antibody sandwich enzyme immunoassay (Human Acylated Ghrelin ELISA; BioVendor Laboratory Medicine, Inc., Modrice, Czech Republic).

\section{Statistical analysis}

For statistical analysis, differences in serum biomarker values, in each group and totally between two groups, were analyzed using two independent sample t-tests. Correlation between all biomarkers in each group were analyzed separately using the bivariate Pearson correlation test. The Receiver Operating Characteristic (ROC) curves were used to find an appropriate cutoff point for each biomarker. All statistical analysis was performed using SPSS version 23. Numeric data were presented as the mean $\pm \mathrm{SD}$, and qualitative data as frequency and percentage were presented. Figures were created using GraphPad Prism 7.0. 
Table 1: Plasma levels of ghrelin and serum levels of pepsinogen I, pepsinogen II, and pepsinogen I/II ratio in both gastric cancer patients and control group patients.

\begin{tabular}{lllll}
\hline & Parameters & & & \\
\hline Groups & Ghrelin $(\mathrm{pg} / \mathrm{L})$ & PG I $(\mu \mathrm{g} / \mathrm{L})$ & PG II $(\mu \mathrm{g} / \mathrm{L})$ & PG I/II ratio \\
Control & $20.85 \pm 13.93$ & $182.23 \pm 139.32$ & $20.97 \pm 21.38$ & $12.19 \pm 8.44$ \\
Gastric cancer & $9.07 \pm 4.50$ & $40.31 \pm 26.43$ & $15.82 \pm 10.10$ & $3.32 \pm 4.01$ \\
$P$ value & $<0.001$ & $<0.001$ & 0.072 & $<0.001$ \\
\hline
\end{tabular}

Data are considered as standard deviation (Means \pm SD)

Table 2: Plasma levels of ghrelin and serum levels of pepsinogen I, II, and their ratio based on alcohol consumption.

\begin{tabular}{|c|c|c|c|c|}
\hline Variables & $\begin{array}{l}\text { Ghrelin } \\
\text { (pg/ml) }\end{array}$ & $\begin{array}{l}\text { Pepsinogen I } \\
(\mu \mathrm{g} / \mathrm{L})\end{array}$ & $\begin{array}{l}\text { Pepsinogen II } \\
(\mu \mathrm{g} / \mathrm{L})\end{array}$ & Pepsinogen I/II ratio \\
\hline \multicolumn{5}{|l|}{ Control } \\
\hline Yes & $15.85 \pm 11.94$ & $227.33 \pm 268.88$ & $36.02 \pm 37.10$ & $9.96 \pm 12.97$ \\
\hline No & $21.54 \pm 14.12$ & $175.97 \pm 112.48$ & $18.87 \pm 17.63$ & $12.50 \pm 7.69$ \\
\hline$P$ value & 0.230 & 0.565 & 0.182 & 0.375 \\
\hline \multicolumn{5}{|c|}{ Gastric cancer } \\
\hline Yes $^{*}$ & 0 & 0 & 0 & 0 \\
\hline No & $9.07 \pm 4.50$ & $40.31 \pm 26.43$ & $15.82 \pm 10.10$ & $3.32 \pm 4.01$ \\
\hline Pvalue & $N D$ & $N D$ & $N D$ & $N D$ \\
\hline
\end{tabular}

* No patients with gastric cancer consumed alcohol.

ND, not determined. Data are considered as standard deviation (Means \pm SD)

\section{Results}

Forty-one patients with GC and 82 healthy volunteers were enrolled in this study as the case and control groups, respectively. Case and control groups were matched in age $(66.98 \pm 13.25$ years old vs. 63.62 \pm 15.90 years old respectively, $\mathrm{P}=0.247$ ), sex (male to female ratio was 1.93 in both group, $\mathrm{P}=1.000)$, and BMI $\left(24.02 \pm 2.42 \mathrm{~kg} / \mathrm{m}^{2}\right.$ vs. $24.74 \pm 2.81 \mathrm{~kg} / \mathrm{m}^{2}$ respectively, $\mathrm{P}=0.168)$. Among the 41 patients with cancer of stomach, 20 had cancer in the gastric cardia and the other 21 individuals had non-cardia cancer. The case group had lower plasma levels of ghrelin, PG I, PG II, and PG I/ II ratio in comparison to the control group, and all these differences, except serum level of PG II, were statistically significant $(\mathrm{P}<0.001$, Table 1). However, no significant differences were detected between the two types of GC for any of the serum or plasma measured biomarkers $(P>0.05$, Figure 1). Although, the PG I/II ratio in non-cardia type of GC was higher than cardia type ( $4.39 \pm 5.43$ vs. $2.19 \pm .0 .45)$, this difference was not statistically significant $(\mathrm{P}=0.078)$. In the case group, significance was seen in lower PG I $(\mathrm{P}=0.006)$ in males versus females and lower plasma

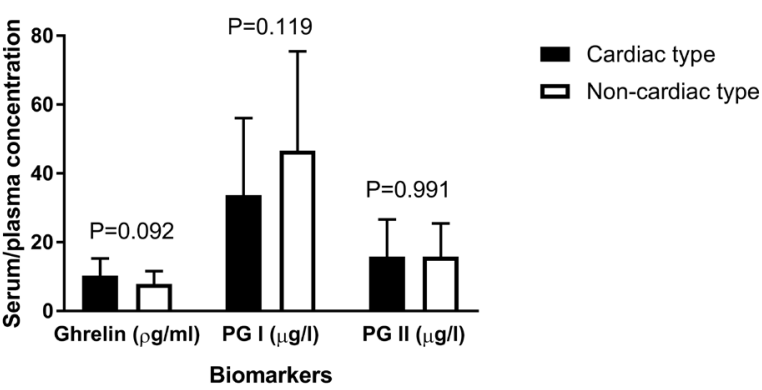

Figure 1: Comparison of plasma ghrelin and serum concentration of PG I and II in two types of gastric cancer. Data are considered as standard deviation (Means \pm SD).

ghrelin in overweight versus normal weight patients $(\mathrm{P}=0.017)$. The control group resulted in significantly higher serum PG I $(\mathrm{P}=0.028)$ and PG II $(\mathrm{P}=0.003)$, and lower $\mathrm{PG} I / \mathrm{II}$ ratio $(\mathrm{P}=0.020)$ in males versus females; significantly higher serum PG II ( $\mathrm{P}=0.047)$ and lower PG I/ II ratio $(\mathrm{P}=0.030)$ in overweight compared to normal weight patients; and significantly lower $\mathrm{PG} \mathrm{I} / \mathrm{II}$ ratio $(\mathrm{P}=0.030)$ in smokers versus non-smoker (Figure 2 and Table 2). 


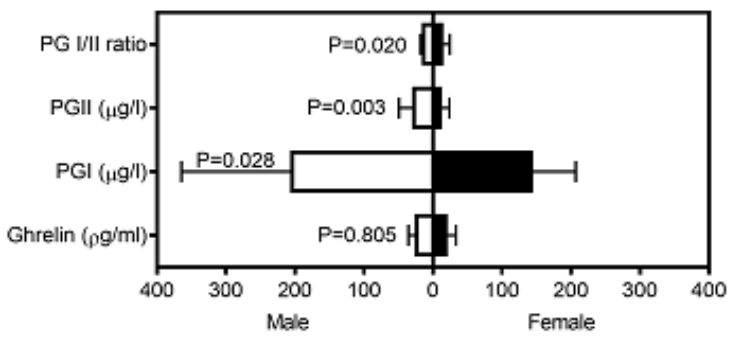

Gender
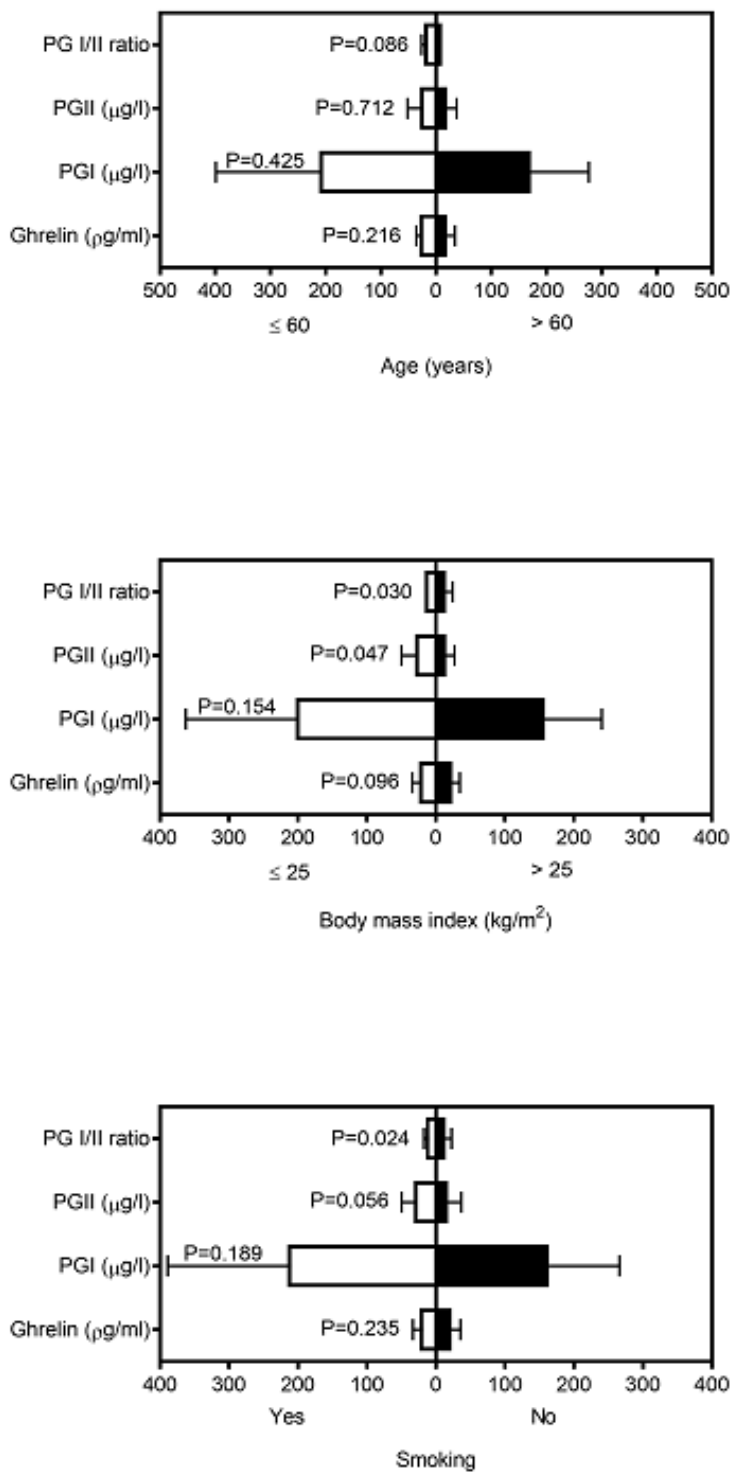

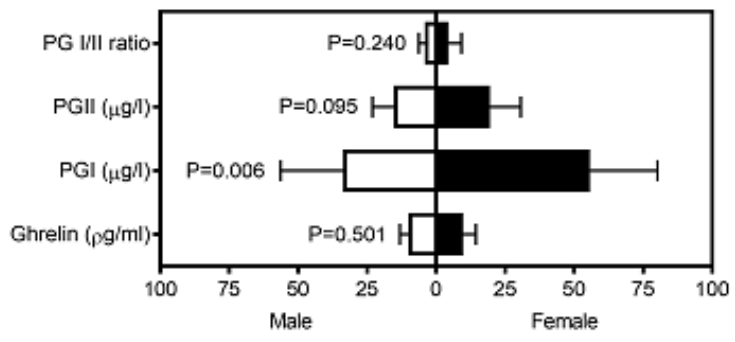

Gender
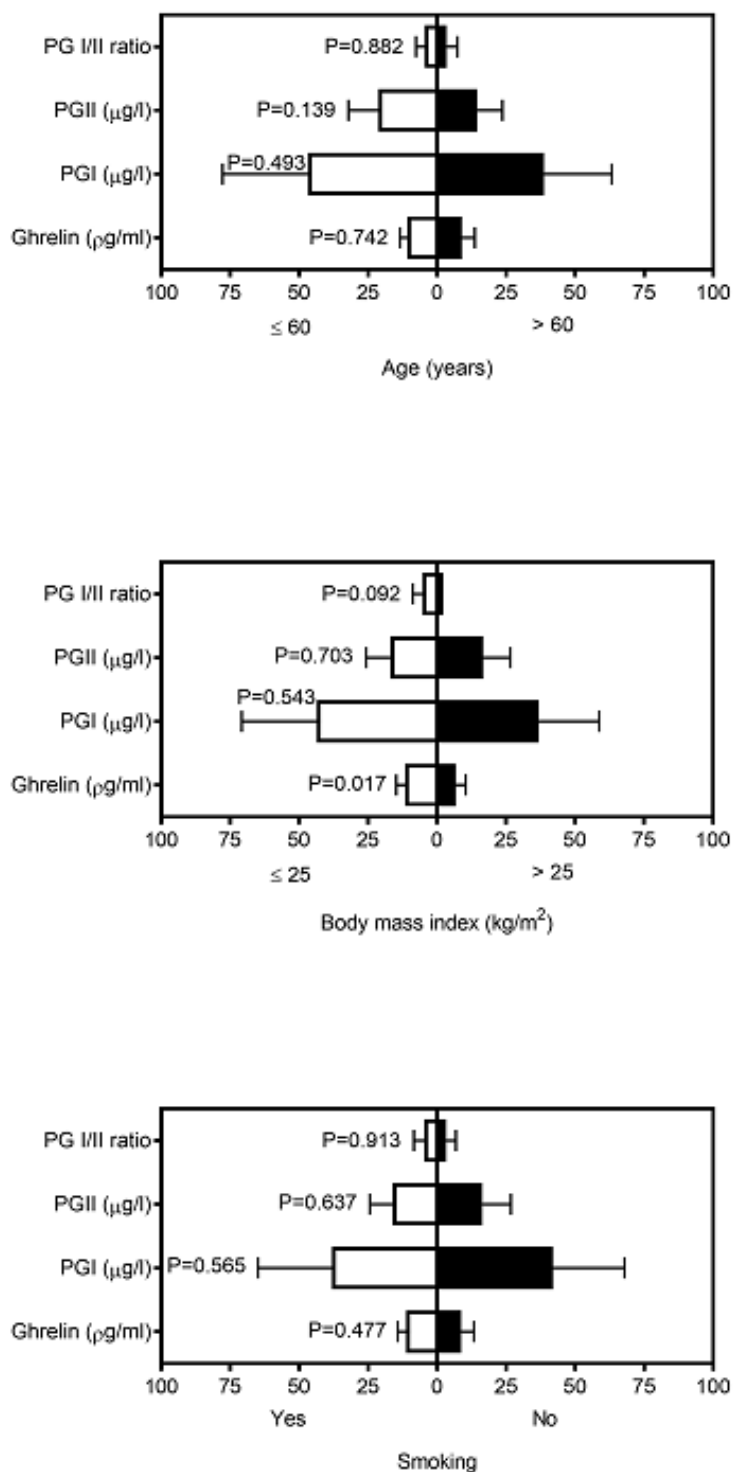

Smoking

Figure 2: Serum levels of ghrelin, pepsinogen I, II, and their ratio based on sex, age, BMI, and smoking categories. Left bar, control group; right bar, gastric cancer group. Data are considered as standard deviation (Means \pm SD). 
Table 3: Correlation analysis between plasma ghrelin levels and serum levels of pepsinogen I and II in control and gastric cancer group. In each group, upper diagonal: Pearson coefficient; lower diagonal: P value.

\begin{tabular}{llllll}
\hline Group & & Ghrelin $(\mathrm{pg} / \mathrm{ml})$ & PG I $(\mu \mathrm{g} / \mathrm{L})$ & PG II $(\mu \mathrm{g} / \mathrm{L})$ & PG I/II ratio \\
\hline Control & Ghrelin & 1 & 0.074 & -0.021 & 0.257 \\
& PG I & 0.509 & 1 & 0.724 & -0.029 \\
& PG II & 0.852 & $<0.001$ & 1 & -0.413 \\
& PG I/II ratio & 0.020 & 0.798 & $<0.001$ & 1 \\
Gastric cancer & & & & 0.147 \\
& Ghrelin & 1 & 0.212 & 0.144 & 0.632 \\
& PG I & 0.184 & 1 & 0.507 & -0.307 \\
\hline
\end{tabular}

Data are considered as standard deviation (Means \pm SD)

Correlation analysis revealed significant associations between PG I and PG II (r: 0.507, P=0.001), and between PG I and PG I/II ratio (r: 0.632, $\mathrm{P}<0.001)$ in the case group, and ghrelin and PG I/II ratio ( $\mathrm{r}$ : 0.257, P=0.020), PG I and PG II (r: 0.724, P<0.001), and PG II and PG I/II ratio (r: -0.413, $\mathrm{P}<0.001$ ) in the control group (Table 3 ). ROC curve analysis indicated that plasma concentration of ghrelin and PG II were not appropriate biomarkers due to low sensitivity and specificity in screening of GCs. However, PG I and PG I/II ratio showed good sensitivity and specificity, and can be used as biomarker to detect suspected GC at a cut-off of $70.95 \mu \mathrm{g} / \mathrm{L}$ and 2.99, respectively (Figure 3 and Table 4).

\section{Discussion}

Investigating all types of serum pepsinogen levels as specific and sensitive biomarkers for screening of GC is of great importance. We aimed to determine optimal cut-off points for plasma levels of ghrelin, and serum levels of pepsinogen I, II, and their ratio for screening of GC. Conspicuously, diagnosis of GC by endoscopy and pathology is too complex and expensive, needs complicated tools, and has low patient compliance. Thus, serological screening using appropriate sensitive and specific biomarkers is very attractive. This study evaluated and compared the plasma levels of ghrelin in addition to serum levels of PG I, II, and their ratio in patients with early diagnosis of GC and a healthy control group to find appropriate biomarkers and their diagnostic cut-offs levels. We found that plasma levels of ghrelin and

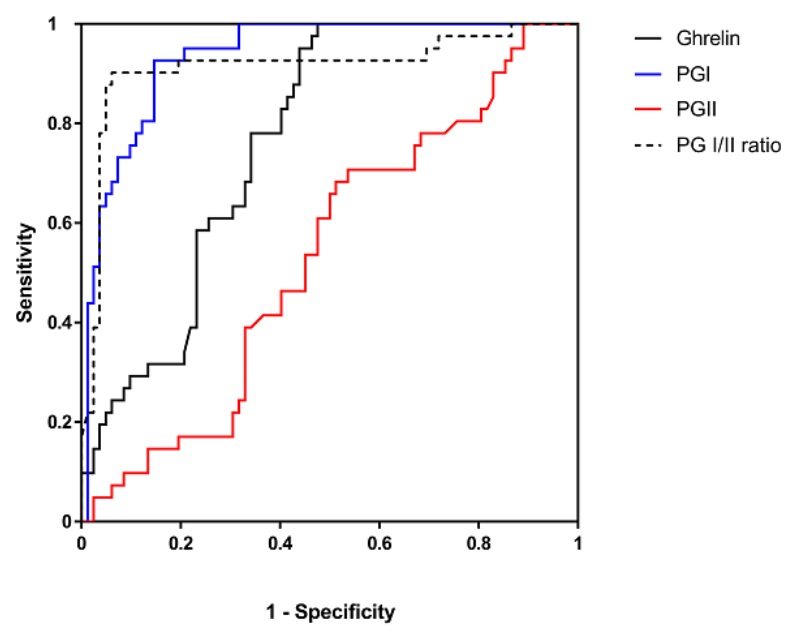

Figure 3: Receiver Operating Characteristic (ROC) curve for ghrelin, PG I, II, and PG I/II ratio for screening of gastric cancer.

serum levels of PG I and PG I/II ratio in patients with GC were significantly lower than healthy ones. Also, gender, BMI, and smoking can induce significant changes in all the above-mentioned biomarkers in both case and control groups. Eventually, serum PG I and PG I/II ratio were confirmed as appropriate biomarker due to good specificity and sensitivity. In a systematic review and meta-analysis with 4241 patients, it has been reported that a combination of pepsinogens with other biomarkers, such as gastrin-17 and serum antibodies against H. pylori, and not pepsinogens alone was a reliable tool to diagnose atrophic gastritis [15]. However, this four tests (used kits) algorithm is expensive and must be evaluated for cost- 
Table 4: ROC curve analysis parameters.

\begin{tabular}{llllllllll}
\hline Biomarkers & Cut-off & \% sensitivity & \% specificity & \%PPV & \%NPV & PLR & NLR & AUC & 95\% CI \\
\hline Ghrelin & 11.42 & 68.29 & 67.07 & 50.91 & 80.88 & 2.07 & 0.47 & $0.77 \pm 0.04$ & $0.69-0.85$ \\
PG I & 70.95 & 92.68 & 85.37 & 76.00 & 95.89 & 6.33 & 0.09 & $0.94 \pm 0.02$ & $0.89-0.98$ \\
PG II & 13.45 & 53.66 & 54.88 & 37.29 & 70.31 & 1.19 & 0.84 & $0.53 \pm 0.05$ & $0.43-0.64$ \\
PG I/II ratio & 2.99 & 90.24 & 93.90 & 88.10 & 95.06 & 14.80 & 0.10 & $0.91 \pm 0.03$ & $0.85-0.98$ \\
\hline
\end{tabular}

PPV, positive predictive value; NPV, negative predictive value; PLR, positive likelihood ratio; NLR, negative likelihood ratio;

AUC, area under the curve. Data are considered as standard deviation (Means \pm SD)

effectiveness. Although, the serum levels of pepsinogens correlate negatively with risk of GCs $[16,17]$ and also their levels are markers of gastric atrophy [18], assessing of pepsinogens alone is reported as inaccurate to diagnose GC and atrophy [19]. Also, the sensitivity ranges of pepsinogens are too wide in different studies from $36.84 \%$ [20] to $90.91 \%$ [21] for detection of GC and from $25.00 \%$ [22] to $91.18 \%$ [23] to detect atrophic gastritis. These differences may be due to several factors such as infection by $H$. pylori [24], age [25], cardia/non-cardia nature of GC, and atrophic gastritis alone or with intestinal metaplasia [19], which can alter the serum pepsinogens levels. Sensitivity and specificity have a negative relationship, when one increases, the another will decrease. Based on optimal cut-off points of all four biomarkers, it is stated that the serum PG I, with a sensitivity of $92.68 \%$ and specificity of $85.37 \%$ for a cut-off of $70.95 \mu \mathrm{g} / \mathrm{L}$, and PG I/II ratio, with a sensitivity of $90.24 \%$ and specificity of $93.90 \%$ for a cut-off of 2.99, have the highest sensitivity and specificity in order to diagnose GC. Oishi et al. also expressed that serum PG I as a level of $70 \mu \mathrm{g} / \mathrm{L}$ was a sensitive and specific biomarker for early detection of GC [16], which is similar to our findings. Similar to our study and Oishi et al.'s report, Miki et al, also found that $80 \%$ of all primary GCs that were diagnosed with routine endoscopy had serum PG I concentration of less than $70 \mu \mathrm{g} / \mathrm{L}$ combined with a PG I/II ratio of less than 3 [26]. However, Dinis-Ribeiro et al. in a meta-analysis found that using serum PG I levels of less than $50 \mu \mathrm{g} / \mathrm{L}$ and PG I/II ratio $<3$ with sensitivity of $65 \%$ and specificity of $74 \%-85 \%$ and negative predictive value of more than $95 \%$ could detect GC [27]. Ghrelin's role in regulating energy balance and weight gain were demonstrated by an increase in appetite and desire to eat [28]. Recently, the roles of ghrelin in the modulation of pathogenesis, progress, and clinical features of cancers were also reported [29,30]. It is confirmed that assessing plasma ghrelin could help to better diagnosis and classify patients with GCs [29]. Similar to significantly lower plasma levels of ghrelin in patients with GC in comparison to healthy control group in this study, Murphy et al. also suggested that lower serum levels of ghrelin were associated with an increased risk of GC [31]. An et al. showed that the serum levels of ghrelin were reduced in inflamed and atrophic gastric tumor tissue in comparison to normal non-tumor gastric tissues [32]. Osawa et al. reported that production of ghrelin by oxyntic mucosal cells in the stomach impaired in chronic gastritis which eventually could presented as a decline in serum ghrelin level [33]. Overall, it can be said that decline of plasma ghrelin in GC may be due to the extent and proliferation of cancer in the stomach and also atrophic gastritis [34]. It has been suggested that age, gender, smoking, alcohol consumption, and body weight are related with serum levels of PG I, II, and ghrelin [35-37]. We found significantly lower plasma ghrelin levels in overweight versus normal weight GC patients. This is in line with the negative correlation between serum ghrelin and BMI that was reported previously [38, 39], but opposite to other reports $[28,40]$. It has been stated that basal ghrelin levels were significantly lower in the overweight/obese group compared with normal weight. Indeed, ghrelin secretion increases in anorexia and cachexia and was reduced in obesity as a signal of the metabolic balance to the central nervous system (CNS ) [38]. Related to gender effects, we found significantly lower PG I in males then in females in the case group, plus significantly higher serum PG I and II, and lower PG I/II ratio in males versus females in the control group. Higher serum levels of PG I in healthy males than females was reported previously [35]. Also, gender and age are can affect the levels of serum pepsinogensin patients with atrophic gastritis and GC [41]. Moreover, Oishi et al. showed a higher hazard ratio for PG I level $\leq 70 \mu \mathrm{g} / \mathrm{L}$ and PG I/II ratio $\leq 3$ in men versus women [16]. Gender differences in PGs is mostly related to the hormone difference not cancer or atrophic gastritis as mentioned previously [35]. Therefore, gender and BMI are confounding factors and they should not be focused on. Smoking is risk factor for certain cancers and, as we have 
seen, healthy control participants with smoking habit had lower PG I/II ratio in comparison to non-smoking. On the other hand, lower PG I/II ratio, as $<2.99$ as we detected in this study, is a highly sensitive and specific biomarker of GC. Therefore, these patients may be cancerous in the future and must be followed-up with. Although age is a confounding factor that induces some changes the serum levels of pepsinogens [42], no significant differences were detected in any of the biomarkers in related to the age in either the control or the case groups.

\section{Limitations}

Although $H$. pylori is a common infectious organism and has been known as the major cause of gastric premalignant and malignant lesions, lack of checking for $H$. pylori infection in either case or control groups is the only limitation of this study. Molecular diagnostic techniques are recommended for better results in gastrointestinal cancers, especially gastric one (43-51). The infection status may alter serum levels of ghrelin [33] and pepsinogens [52], and must be addressed in the future studies performed in our center.

\section{Conclusion}

In the present study, we tried to determine a cut-off point for plasma ghrelin level as well as for serum PG I, II, and their ratio for detection of GC. We found that just PG I, with high sensitivity and moderate specificity, and PG I/II ratio, with high sensitivity and high specificity, could detect GC effectively. Patients with GC had lower serum PG II and lower plasma ghrelin in comparison to healthy control group, but these two biomarkers had low sensitivity and low specificity in detection of GC. Since, this study is among the first primary studies that have obtained a cut-off point to determine the following serum and plasma levels of biomarkers, further studies are required to increase validity and reliability of the cut-off points. Then, cut-off points could be used with a high reliability level in daily clinical practice of practitioners.

Conflict of interest: Authors state no conflict of interest

\section{References}

1. Crew KD, Neugut Al. Epidemiology of gastric cancer. World Journal of Gastroenterology. 2006;12(3):354.

2. Kamangar F, Dores GM, Anderson WF. Patterns of cancer incidence, mortality, and prevalence across five continents: defining priorities to reduce cancer disparities in different geographic regions of the world. Journal of Clinical Oncology. 2006;24(14):2137-50.

3. Yanaoka K, Oka M, Yoshimura N, Mukoubayashi C, Enomoto $\mathrm{S}$, Iguchi $\mathrm{M}$, et al. Risk of gastric cancer in asymptomatic, middle-aged Japanese subjects based on serum pepsinogen and Helicobacter pylori antibody levels. International Journal of Cancer. 2008;123(4):917-26.

4. Boyd J, Langman M, Doll R. The epidemiology of gastrointestinal cancer with special reference to causation. Gut. 1964;5(2):196-200.

5. Alireza S, Mehdi N, Ali M, Alireza M, Reza M, Parkin D. Cancer occurrence in Iran in 2002, an international perspective. Asian Pacific journal of cancer prevention. 2005;6(3):359.

6. Malekzadeh R, Derakhshan MH, Malekzadeh Z. Gastric cancer in Iran: epidemiology and risk factors. Archive of Iranian Medicine. 2009;12(6):576-83.

7. Mansour-Ghanaei F, Joukar F, Soati F, Mansour-Ghanaei A, Naserani SB. Knowledge about gastric carcinoma in North of Iran, a high prevalent region for gastric carcinoma: a population-based telephone survey. Asian Pacific Journal of Cancer Prevention. 2012;13(7):3361-6.

8. Atrkar-Roushan Z, Kazemnejad A, Mansour-Ghanaei F, Zayeri F. Trend analysis of gastrointestinal cancer incidences in Guilan province: comparing rates over 15 years. Asian Pacific Journal of Cancer Prevention. 2013;14(12):7587-93.

9. Borch K, Axelsson CK, Halgreen H, Nielsen MD, Ledin T, Szesci PB. The ratio of pepsinogen A to pepsinogen C: $\mathrm{a}$ sensitive test for atrophic gastritis. Scandinavian Journal of Gastroenterology. 1989;24(7):870-6.

10. Takiguchi S, Takata A, Murakami K, Miyazaki Y, Yanagimoto Y, Kurokawa Y, et al. Clinical application of ghrelin administration for gastric cancer patients undergoing gastrectomy. Gastric Cancer. 2014;17(2):200-5.

11. Foltmann B. Gastric proteinases--structure, function, evolution and mechanism of action. Essays in Biochemistry. 1981;17:52.

12. Ichikawa H, Sugimoto M, Sakao Y, Sahara S, Ohashi N, Kato A, et al. Relationship between ghrelin, Helicobacter pylori and gastric mucosal atrophy in hemodialysis patients. World Journal of Gastroenterology. 2016;22(47):10440-9.

13. Murphy G, Cross AJ, Dawsey SM, Stanczyk FZ, Kamangar F, Weinstein SJ, et al. Serum ghrelin is associated with risk of colorectal adenocarcinomas in the ATBC study. Gut. 2017.

14. Murphy G, Kamangar F, Albanes D, Stanczyk FZ, Weinstein SJ, Taylor PR, et al. Serum ghrelin is inversely associated with risk of subsequent oesophageal squamous cell carcinoma. Gut. 2012;61(11):1533-7.

15. Zagari RM, Rabitti S, Greenwood DC, Eusebi LH, Vestito A, Bazzoli F. Systematic review with meta-analysis: diagnostic performance of the combination of pepsinogen, gastrin-17 and anti-Helicobacter pylori antibodies serum assays for the diagnosis of atrophic gastritis. Alimentary pharmacology \& therapeutics. 2017;46(7):657-67. 
16. Oishi Y, Kiyohara Y, Kubo M, Tanaka K, Tanizaki Y, Ninomiya $\mathrm{T}$, et al. The serum pepsinogen test as a predictor of gastric cancer: the Hisayama study. American Journal of Epidemiology. 2006;163(7):629-37.

17. Yanaoka K, Oka M, Mukoubayashi C, Yoshimura N, Enomoto $\mathrm{S}$, Iguchi $\mathrm{M}$, et al. Cancer high-risk subjects identified by serum pepsinogen tests: outcomes after 10-year follow-up in asymptomatic middle-aged males. Cancer Epidemiology and Prevention Biomarkers. 2008;17(4):838-45.

18. Agréus L, Kuipers EJ, Kupcinskas L, Malfertheiner P, Di Mario $\mathrm{F}$, Leja $\mathrm{M}$, et al. Rationale in diagnosis and screening of atrophic gastritis with stomach-specific plasma biomarkers. Scandinavian Journal of Gastroenterology. 2012;47(2):136-47.

19. Huang Y-k, Yu J-c, Kang W-m, Ma Z-q, Ye X, Tian S-b, et al. Significance of serum pepsinogens as a biomarker for gastric cancer and atrophic gastritis screening: a systematic review and meta-analysis. PloS one. 2015;10(11):e0142080.

20. Mizuno S, Kobayashi M, Tomita S, Miki I, Masuda A, Onoyama $M$, et al. Validation of the pepsinogen test method for gastric cancer screening using a follow-up study. Gastric Cancer. 2009;12(3):158-63.

21. Huang YY, Cheng WC, Gao N, Ye N, Qian YT. The diagnostic value of serum pepsinogen I, II for gastric cancer and precancerous lesions of gastric cancer detection. Chinese Journal of Internal Medicine. 2013;52(4):332-3.

22. Sitas F, Smallwood R, Jewell D, Millard PR, Newell DG, Meuwissen SG, et al. Serum anti-Helicobacter pylori IgG antibodies and pepsinogens $A$ and $C$ as serological markers of chronic atrophic gastritis. Cancer Epidemiology and Prevention Biomarkers. 1993;2(2):119-23.

23. Sierra R, Une C, Ramirez V, González MI, Ramirez JA, De Mascarel A, et al. Association of serum pepsinogen with atrophic body gastritis in Costa Rica. Clinical and Experimental Medicine. 2006;6(2):72-8.

24. Leja M, Park JY, Murillo R, Liepniece-Karele I, Isajevs S, Kikuste I, et al. Multicentric randomised study of Helicobacter pylori eradication and pepsinogen testing for prevention of gastric cancer mortality: the GISTAR study. BMJ open. 2017;7(8):e016999.

25. Yaghoobi M, Bijarchi R, Narod SA. Family history and the risk of gastric cancer. British journal of cancer. 2010;102(2):237-42.

26. Miki K, Fujishiro M, Kodashima S, Yahagi N. Long-term results of gastric cancer screening using the serum pepsinogen test method among an asymptomatic middle-aged Japanese population. Digestive Endoscopy. 2009;21(2):78-81.

27. Dinis-Ribeiro M, Yamaki G, Miki K, Costa-Pereira A, Matsukawa $M$, Kurihara M. Meta-analysis on the validity of pepsinogen test for gastric carcinoma, dysplasia or chronic atrophic gastritis screening. Journal of Medical Screening. 2004;11(3):141-7.

28. Stensel D. Exercise, appetite and appetite-regulating hormones: implications for food intake and weight control. Annals of Nutrition and Metabolism. 2010;57(Suppl. 2):36-42.

29. Soleyman-Jahi S, Abdirad A, Fallah AA, Ghasemi S, Sadeghi F, Heidari R, et al. Prognostic Significance of Preoperative and Postoperative Plasma Levels of Ghrelin in Gastric Cancer: 3-Year Survival Study. Clinical and translational gastroenterology. 2017;8(1):e209.

30. Kawaguchi M, Kanemaru A, Fukushima T, Yamamoto K, Tanaka $\mathrm{H}$, Haruyama $\mathrm{Y}$, et al. Ghrelin administration suppresses inflammation-associated colorectal carcinogenesis in mice. Cancer Science. 2015;106(9):1130-6.

31. Murphy G, Kamangar F, Dawsey SM, Stanczyk FZ, Weinstein SJ, Taylor PR, et al. The relationship between serum ghrelin and the risk of gastric and esophagogastric junctional adenocarcinomas. Journal of the National Cancer Institute. 2011;103(14):1123-9.

32. An JY, Choi M-G, Noh JH, Sohn TS, Jin D-K, Kim S. Clinical significance of ghrelin concentration of plasma and tumor tissue in patients with gastric cancer. Journal of Surgical Research. 2007;143(2):344-9.

33. Osawa H, Nakazato M, Date Y, Kita H, Ohnishi H, Ueno H, et al. Impaired production of gastric ghrelin in chronic gastritis associated with Helicobacter pylori. The Journal of Clinical Endocrinology \& Metabolism. 2005;90(1):10-6.

34. Zub-Pokrowiecka A, Rembiasz K, Konturek PC, Budzyński A, Konturek SJ, Winiarski M, et al. Ghrelin and gastrin in advanced gastric cancer before and after gastrectomy. World Journal of Gastroenterology. 2011;17(4):449-58.

35. Kim HY, Kim N, Kang JM, Park YS, Lee DH, Kim YR, et al. Clinical meaning of pepsinogen test and Helicobacter pylori serology in the health check-up population in Korea. European journal of gastroenterology \& hepatology. 2009;21(6):606-12.

36. Hokkanen S, Kosunen TU, Sarna S, Miettinen A, Salomaa A, Aromaa A, et al. Normal serum pepsinogen I levels in adults: a population-based study with special reference to Helicobacter pylori infection and parietal cell antibodies. Scandinavian journal of clinical and laboratory investigation. 2005;65(4):2919.

37. Cummings DE, Purnell JQ, Frayo RS, Schmidova K, Wisse BE, Weigle DS. A preprandial rise in plasma ghrelin levels suggests a role in meal initiation in humans. Diabetes. 2001;50(8):17149.

38. Tash RME, El-Dydamoni OA, Ezzat AA, Badr BMA, Radwan EE, Ahmed MI. Ghrelin and leptin in obese postmenopausal patients. Clinical Medicine and Diagnostics. 2016;6(3):77-83.

39. Heshmat R, Shafiee G, Qorbani M, Azizi-Soleiman F, Djalalinia $\mathrm{S}$, Esmaeil Motlagh M, et al. Association of ghrelin with cardiometabolic risk factors in Iranian adolescents: the CASPIAN-III study. Journal of Cardiovascular and Thoracic Research. 2016;8(3):107-12.

40. Marzullo P, Verti B, Savia G, Walker GE, Guzzaloni G, Tagliaferri M, et al. The relationship between active ghrelin levels and human obesity involves alterations in resting energy expenditure. The Journal of Clinical Endocrinology \& Metabolism. 2004;89(2):936-9.

41. Kim N, Jung HC. The role of serum pepsinogen in the detection of gastric cancer. Gut and Liver. 2010;4(3):307-19.

42. Shan JH, Bai XJ, Han LL, Yuan Y, Sun XF. Changes with aging in gastric biomarkers levels and in biochemical factors associated with Helicobacter pylori infection in asymptomatic Chinese population. World Journal of Gastroenterology. 2017;23(32):5945-53.

43. Samadani AA, Norollahi SE, Rashidy-Pour A, Mansour-Ghanaei F, Nemati S, Joukar F, et al. Cancer signaling pathways with a therapeutic approach: An overview in epigenetic regulations of cancer stem cells. Biomed Pharmacother. 2018;108:590-599.

44. Samadani AA, Noroollahi SE, Mansour-Ghanaei F, Rashidy-Pour A, Joukar F, Bandegi AR. Fluctuations of epigenetic regulations 
in human gastric Adenocarcinoma: How does it affect? Biomed Pharmacother. 2019;109:144-156.

45. Samadani AA, Nikbakhsh N, Pilehchian M, Fattahi S, Akhavan-Niaki H. Epigenetic changes of CDX2 in gastric adenocarcinoma.J Cell Commun Signal. 2016;10(4):267-272.

46. Pilehchian Langroudi M, Nikbakhsh N, Samadani AA, Fattahi $\mathrm{S}$, Taheri H, Shafaei S, et al. FAT4 hypermethylation and grade dependent downregulation in gastric adenocarcinoma.J Cell Commun Signal. 2017;11(1):69-75.

47. Norollahi SE, Alipour M, Rashidy-Pour A, Samadani AA, Larijani LV. Regulatory Fluctuation of WNT16 Gene Expression Is Associated with Human Gastric Adenocarcinoma,J Gastrointest Cancer. 2019;50(1):42-47.

48. Kosari-Monfared M, Nikbakhsh N, Fattahi S, Ghadami E, Ranaei $\mathrm{M}$, Taheri $\mathrm{H}$, et al. CTNNBIP1 downregulation is associated with tumor grade and viral infections in gastric adenocarcinoma.J Cell Physiol. 2019;234(3):2895-2904.

49. Ghadami E, Nikbakhsh N, Fattahi S, Kosari-Monfared M, Ranaee M, Taheri H, et al. Epigenetic alterations of CYLD promoter modulate its expression in gastric adenocarcinoma: A footprint of infections.J Cell Physiol. 2019;234(4):4115-4124.

50. Samadani AA, Nikbakhsh N, Taheri H, Shafaee S, Fattahi S, Pilehchian Langroudi M, et al. CDX1/2 and KLF5 Expression and Epigenetic Modulation of Sonic Hedgehog Signaling in Gastric Adenocarcinoma. Pathol Oncol Res. 2019; https://doi. org/10.1007/s12253-019-00594-4

51. Fattahi S, Nikbakhsh N, Taheri H, Ghadami E, Kosari-Monfared $\mathrm{M}$, Amirbozorgi $\mathrm{G}$, et al. Prevalence of multiple infections and the risk of gastric adenocarcinoma development at earlier age. Diagn Microbiol Infect Dis. 2018;92(1):62-68.

52. Osumi H, Fujisaki J, Suganuma T, Horiuchi Y, Omae M, Yoshio $\mathrm{T}$, et al. A significant increase in the pepsinogen $\mathrm{I} / \mathrm{II}$ ratio is a reliable biomarker for successful Helicobacter pylori eradication. PloS one. 2017;12(8):e0183980. 